\title{
Genetic evidence of extra-pair paternity and intraspecific brood parasitism in the monk parakeet
}

\author{
Juan José Martínez ${ }^{1,5}$, María Carla de Aranzamendi ${ }^{2}$, Juan F Masello ${ }^{3}$ and Enrique H Bucher ${ }^{4^{*}}$
}

\begin{abstract}
Introduction: The monk parakeet (Myiopsitta monachus) is a widespread invasive species native to southern South America that has become established in many regions of the world. Monk parakeets breed in a large, fully enclosed structure built from twigs, which consist of one to many individual brooding chambers. The species has been considered to be socially and genetically monogamous. However, genetic relatedness of adults to juveniles in the native area was found to be lower than expected for monogamy. To assess the significance of this discrepancy, we examined individual and population genetic patterns of microsatellite loci at two sites in Córdoba province, Argentina.

Results: We sampled 154 nestlings and 42 adults in Córdoba, Argentina. Mean value of pairwise relatedness of nestlings within chambers was about 0.40 . Contrarily, relatedness of nestlings between chambers was close to zero. We found a considerable degree of variation in nestling pairwise relatedness and parentage within chambers, including chambers with combinations of unrelated, half-sib, and full-sib nestlings. The proportion of sibling relatedness indicated monogamy in $47 \%$ and extra pair-paternity in $40 \%$ of the chambers. We also found intra-brood parasitism in $3 \%$ of the chambers.

Conclusions: Our results indicate that the monk parakeet is sexually polygamous in its native range in Argentina, which is consistent with the observed mean value of relatedness of adults to juveniles of about 0.4. We also confirm the existence of intra-brood parasitism. High density of monk parakeets may favor occurrence of extra-pair paternity and intra-brood parasitism in the native sites.
\end{abstract}

Keywords: Parrots, Extra-pair paternity, Intra-brood parasitism, Breeding biology, Argentina

\section{Introduction}

The monk parakeet is a South American species unique among parrots because its communal nests allow independence from tree or cliff cavities as the required breeding habitat by most parrots. Nesting habitat flexibility may contribute substantially to the considerable success of the monk parakeet as an invasive species, having already expanded in several countries in South, Central and North America, as well as in Europe, the Caribbean and Japan [1]. In addition,

\footnotetext{
* Correspondence: buchereh@gmail.com

${ }^{4}$ Centro de Zoología Aplicada. Instituto de Diversidad y Ecología Animal (CONICET-UNC) and Facultad de Ciencias Exactas, Físicas y Naturales, Universidad Nacional de Córdoba, Avenida Vélez Sarsfield 299, (5000) Córdoba, Argentina

Full list of author information is available at the end of the article
}

in many regions the monk parakeet is considered a problem for agriculture and also for electricity transmission lines [2]. Accordingly, the monk parakeet has attracted considerable attention and research effort, not only because of practical management needs, but also because of its unique ecological and behavioural characteristics [3].

Monk parakeets nest in a large, fully enclosed bulky structure, built from twigs on the topmost branches of a tree. They build the nest by adding individual brooding chambers, each with its own entrance tunnel and no connection between compartments, where they lay the eggs [4]. Accordingly, nests may include from a single chamber up to over 200 chambers, although in natural settings nests typically include $1-4$ chambers $[3,5]$. Nests are used not only for breeding, but also as

\section{Biomed Central}


roosting quarters by breeding and non-breeding monk parakeets throughout the year, and they always roost inside a nest.

The monk parakeet has been reported to be socially and genetically monogamous [4-6]. However, breeding attempts including trios have been reported occasionally $[5,7]$. In recent years, a study on population genetics has provided valuable information on the breeding behaviour of the monk parakeet. Gonçalves da Silva et al. [6] found strong evidence for sexual monogamy from patterns of relatedness within sites in native monk parakeet populations of Argentina (60 individuals) and invasive populations of the United States (195 individuals). Secondly, the authors found no definite cases of extra-pair paternity in either population.

However, Gonçalves da Silva et al. [6] also found that mean relatedness of both adult females and males to juveniles in Argentina was significantly lower than the expected genetic relatedness value $(0.5)$ for monogamy. In addition, they also found one potential instance of extra-pair paternity in Argentina, which was disregarded due to limited information available at the moment of conducting their research. Accordingly, and in view of the low relatedness value found in Argentina, Gonçalves da Silva et al. [6] suggested a wider geographical sampling to ascertain the biological significance of the observed difference between Argentina and USA populations.

Clearly, this open question is of fundamental importance in terms of the understanding of the monk parakeet breeding behaviour, and also in the context of possible behavioural differences between native and invasive sites that may have emerged in the invasive sites [6]. Here we present an analysis of relatedness, sibship reconstruction and extra-pair paternity analysis in monk parakeet nests from two 20-km distant sites in central Argentina (i.e., Marull and Miramar, Córdoba province), using a microsatellite-based genotyping method. Specifically, we investigated: (1) the relatedness between nestlings in each breeding chamber in single and multichambered nests; (2) the relatedness between nestlings from different chambers within the same compound nest; (3) the paternity and maternity of adults captured in nests. Special attention was given to the possible existence of extra-pair paternity and intra-brood brood parasitism.

\section{Results}

We sampled 28 nests with 37 chambers distributed as follows: 21 chambers in single-chamber nests, 12 in six two-chamber nests, and four in one four-chamber nest. We captured and blood sampled 154 nestlings and 42 adults. Of the adults, 21 were males and 20 females (one individual was not able to be sexed due to the failure in amplify the sex-linked molecular marker). Nestling-adult relationship was found in 18 adults.

Of the remaining 24 adults with no parentage relationship, 18 were trapped in the studied nests (listed in Additional file 1), whereas six additional individuals were captured in the Miramar area in nests not included in the nestling sampling.

\section{Genetic variation}

The analyses to detect the presence of null alleles were significant in five of seven loci (AgGT019, AgGT029, AgGT090, MmGT054 and MmGT057). However, only the loci AgGT090 and MmGT054 deviated significantly from Hardy-Weinberg $(\mathrm{H}-\mathrm{W})$ equilibrium when the three data sets were taken into account (i.e., adults, juveniles and, adults and juveniles together) (data not shown). Even though those loci presented evidence for the occurrence of null alleles, we included these loci in further analyses due to their high polymorphism, following Wagner et al. [8] (Additional file 2).

The results of AMOVA are shown in Table 1. Genetic variation was explained by within-individuals partition (78\%), whereas differences among individuals within localities explained $21 \%$ of the genetic variation observed. The between-sites partition was not significant.

\section{Patterns of relatedness in nests Nestlings}

Mean value of pairwise relatedness of nestlings within chambers (including chambers in compound nests) was about 0.41 for both localities, a lower value than that expected under sexual monogamy (0.50) (Table 2) and consistent with the previous study. Figure 1 depicts the variation of pairwise relatedness within chambers with more than three nestlings. Contrarily, mean value of pairwise relatedness of nestlings between chambers was zero in Miramar and close to zero in Marull. For cases

\begin{tabular}{|c|c|c|c|}
\hline $\begin{array}{l}\text { (A) Source } \\
\text { of variation }\end{array}$ & $\begin{array}{l}\text { Sum of } \\
\text { squares }\end{array}$ & $\begin{array}{c}\text { Variance } \\
\text { components }\end{array}$ & $\begin{array}{l}\text { Percentage } \\
\text { of variation }\end{array}$ \\
\hline $\begin{array}{l}\text {-Between sites (Marull } \\
\text { and Miramar) }\end{array}$ & 4.104 & 0.024 & 0.917 \\
\hline $\begin{array}{l}\text {-Among individuals } \\
\text { within sites }\end{array}$ & 123.384 & 0.554 & 21.069 \\
\hline -Within individuals & 84.500 & 2.051 & 78.015 \\
\hline -Total & 211.988 & 2.629 & \\
\hline (B) Fixation index & Estimated value $(P)$ & & \\
\hline$F_{i s}$ & $0.213(<0.001)$ & & \\
\hline$F_{s t}$ & $0.009(0.801)$ & & \\
\hline$F_{i t}$ & $0.219(<0.001)$ & & \\
\hline
\end{tabular}


Table 2 Population structure of pairwise relatedness values

\begin{tabular}{|c|c|c|c|c|c|}
\hline \multirow[t]{3}{*}{ Pairwise comparisons } & \multirow{3}{*}{$\begin{array}{l}\text { Expected } \\
\text { value } \\
\text { under } \\
\text { sexual } \\
\text { monogamy }\end{array}$} & \multicolumn{4}{|c|}{ Location } \\
\hline & & \multicolumn{2}{|c|}{ Marull } & \multicolumn{2}{|c|}{ Miramar } \\
\hline & & Comparisons $\mathbf{N}$ & Mean $(95 \% \mathrm{Cl})$ & Comparisons $\mathrm{N}$ & Mean $(95 \% \mathrm{Cl})$ \\
\hline Individuals within chambers & 0.5 & 80 & $0.418(0.355-0.482)$ & 215 & $0.415(0.381-0.448)$ \\
\hline Individuals among chambers & 0.0 & 866 & $0.034(0.019-0.049)$ & 5780 & $-0.049(-0.055--0.044)$ \\
\hline Adult females to juveniles within nests & 0.5 & 50 & $0.162(0.085-0.238)$ & 107 & $0.229(0.178-0.279)$ \\
\hline Adult females to juveniles among nests & 0.0 & 302 & $-0.053(-0.076--0.029)$ & 1213 & $-0.035(-0.047--0.023)$ \\
\hline Adult males to juveniles within nests & 0.5 & 44 & $0.214(0.127-0.301)$ & 114 & $0.171(0118-0.224)$ \\
\hline Adult males to juveniles among nests & 0.0 & 264 & $0.041(0.013-0.068)$ & 1426 & $-0.018(-0.029--0.007)$ \\
\hline
\end{tabular}

of nests with two or more chambers, the mean pairwise relatedness among juveniles was very low, zero in Miramar and close to zero in Marull.

\section{Adults}

Comparison of adult to juvenile relatedness within and among nests indicates some slight differences between localities. Mean pairwise relatedness between candidate mothers and juveniles was low in relation to the expected value for sexual monogamy (0.5). Observed mean value in Miramar was slightly higher than in Marull. Mean pairwise relatedness between candidate fathers and juveniles showed values similar to those found in females, although in Miramar the mean relatedness value was lower than in Marull (Table 2).

\section{Variations in genetic relatedness among nests and chambers}

We found a considerable degree of variation in nestling pairwise relatedness and parentage within chambers, including chambers with combinations of unrelated, halfsibs, and full-sibs nestlings (Additional file 1). Of the 37 chambers with nestlings, the proportion of different degrees of sibling relatedness was as follows: 18 (47\%) had full-sibs, with two of them also having one (in one case) or two (in two cases) unrelated individuals; 15 (40\%) had combinations of half- and full-sibs, and one (3\%) had one unrelated individual. We also found genetic parents in different nests or chambers from their nestling location (Additional file 1).

In the remaining four chambers $(10 \%)$ we were not able to determine relatedness with acceptable probability (three cases with a single nestling and one case with five nestlings and three adults) (Additional file 1).

With regards to adults captured in nests, in five of the nine monogamy chambers with adults we found the genetic pair with their nestlings in the breeding chamber. In two other chambers, only the genetic mother was present, together with one and three unrelated adults, respectively. In the remaining three chambers we found unrelated adults only. We found adults genetically related to the nestlings in four of the seven polygamy chambers. In one case the two genetic parents (of a subgroup of three half-sib nestlings in a clutch of five) were

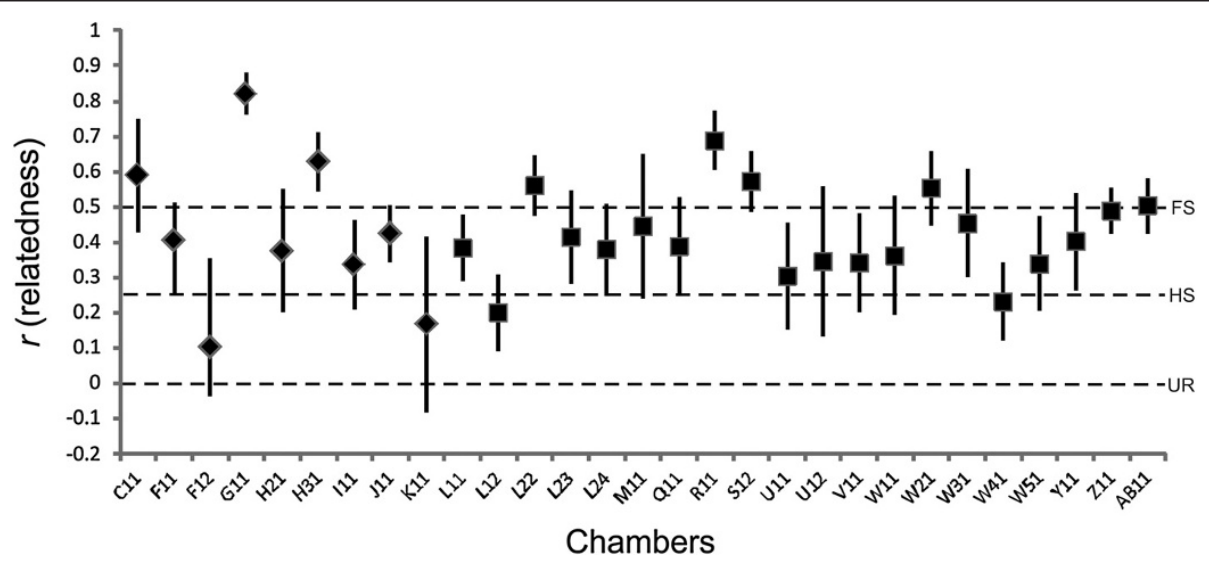

Figure 1 Mean pairwise relatedness values $(r)$ for nestlings within chambers. Dotted lines indicate expected values of relatedness for UR: unrelated $(r=0)$, HS: half-sibs $(r=0.25)$ and FS: full-sibs $(r=0.5)$. Diamonds: chambers from Marull; Squares: chambers from Miramar. 
in the breeding chamber. In three other chambers we trapped only one genetic parent. The remaining three chambers had unrelated individuals only (Additional file 1).

\section{Discussion}

Our study confirms that values below the 0.5 threshold in monk parakeet adult-juvenile relatedness are widespread in Argentina, adding to a similar value found by Gonçalves et al. [6] in a population sampled in Entre Rios province (about $400 \mathrm{~km}$ east from our sites in Cordoba).

The observed low relatedness values are clearly consistent with occurrence of a significant rate of extra-pair paternity in about half of the sampled breeding chambers, together with cases of intra-brood parasitism.

Further evidence is provided by the three detected cases of adult males with nestlings in two different nests. A potential case of extra-pair paternity in the monk parakeet was first mentioned by Gonçalves et al. in Entre Rios, Argentina [6], which was disregarded, although the authors mentioned that their approach might be too conservative.

Our finding of extra-pair paternity in monk parakeet drastically changes the until now generalized concept of almost absolute prevalence of monogamy among parrots [9], since no conclusive evidence of extra-pair paternity has been found previously, including a detailed study of the colonial breeding burrowing parrot (Cyanoliseus patagonus) [10]. It is likely, however, that further research may find new cases of polygamy in the Psittacidae, given that since application of molecular techniques extra-pair paternity has been found to occur widely in birds [11]. For example, there is preliminary evidence of extra-pair paternity in the African echo parakeet (Psittacula eques) [12], and in the blue-and-yellow macaw (Ara ararauna) [13].

Variations in intraspecific reproductive strategies between native and invasive sites may result from an adaptive response to environmental changes or population density [14]. Although inconclusive, there is good evidence that breeding density may be important in determining variation in the extra-pair paternity rate at the species level, as shown by Møller \& Ninni [15] and Westneat \& Sherman [16]. In this regard, our two localities (Marull and Miramar) are located in an area of high monk parakeet density in the province of Córdoba [17], whereas it is likely that populations in invasive sites are still growing, and therefore less dense than areas that sustain long-time occupation as in Córdoba. Differences in density may explain therefore the higher relatedness values found in the USA by Gonçalves et al. [6].

Existence of intra-brood parasitism in the monk parakeet is based on the finding of three chambers with four nestlings unrelated to the rest of the brood ( $3 \%$ of the 154 nestlings sampled). The three cases correspond to nests with more than one chamber, suggesting that intra-brood parasitism may be related to multi-chambered nests. This possibility is further supported by the capture of the mother of one unrelated nestling in the neighbour chamber of the same nest (Additional file 1).

Additional evidence of intra-brood parasitism in monk parakeets is provided by the finding of supernumerary clutches of about twice the average number $[18,19]$. In a detailed study of a monk parakeet nest [18], the author found a single chamber with supernumerary clutches for two consecutive years (12 and 11 eggs, respectively). Eggs were initially laid every second day, but after a while, new eggs appeared daily (one or two). Later, egglaying returned to the initial rhythm until the end of the period. According to Yom-Tov [20], irregular sequence of appearance of eggs and abnormally large clutches of about twice the normal size suggest that the extra eggs were laid by more than one female.

Occurrence of intra-brood parasitism has also been recorded in the burrowing parrot, with two cases of unrelated nestlings found in a sample of 166 nestlings (1.2\%) [10]. One of these cases may have resulted from brood mixing from a neighbouring nest with a collapsed wall. However, the second case could not be explained by brood mixing, and therefore most likely resulted from intraspecific brood parasitism. Even if brood mixing cannot be discarded in monk parakeet nests, in our case this possibility is unlikely, given that all collected nestlings were very young and therefore unable to displace by themselves. The probable occurrence of intra-brood parasitism was also reported in the green-rumped parrotlet (Forpus passerinus) by Beissinger \& Waltman [21], based on the existence of larger than average clutches.

High population density may also favor intra-brood parasitism. Supporting evidence indicating that in some bird populations high population density was correlated with nest parasitism was reviewed by Spoon [9] and Griffith et al. [11]. Another possible factor favouring intra-brood parasitism is colonial breeding, and particularly the close proximity of nests (chambers) in the monk parakeet communal nests. Rohwer \& Freeman [22] found evidence of greater conspecific nest parasitism in those parentally fed species that nest in colonies, as compared with species with dispersed nests.

It is also likely that occurrence of extra-pair paternity and intra-brood parasitism may be favoured in areas of high monk parakeet density where nests have a larger number of breeding chambers in the same compound nests, and also nests tend to group in close proximity either in the same or neighbouring trees forming the so called "colonies" [5], in contrast with invasive sites with lower density and smaller size of the compound nests. Unfortunately, understanding the adaptive significance 
of both extra-pair paternity and intra-brood parasitism in the monk parakeet is constrained by the limited information available on the species' life story, hindering a more comprehensive analysis of the interaction and conflicts of life-history traits [23].

\section{Conclusions}

Our results confirm that in the monk parakeet native range in Argentina mean values of relatedness of adults to juveniles are lower than expected for monogamy. We also found evidence of important levels of extra-pair paternity (40\% of chambers) and four cases of intra-brood parasitism in $3 \%$ of chambers.

\section{Materials and methods}

\section{Sampling sites and field methods}

Samples were collected from two sites located $20 \mathrm{~km}$ apart in central Argentina (Córdoba province): Marull (31 40' S, 62 $49 \mathrm{~W}$ ) and Miramar (32 $55^{\circ} \mathrm{S}, 6^{\circ} 40^{\prime}$ $\mathrm{W})$. Both localities are situated in the Pampas ecoregion, a vast plain landscape that is almost entirely used for agriculture. Nests were examined during the last week of November and the first week of December 2000. During that period, all breeding chambers contained only young, flightless nestlings, since the monk parakeet has a highly synchronized, single annual brood [19].

Nests were located in eucalyptus tree rows along fences, over $15 \mathrm{~m}$ above ground level. We reached the nests during the night using a cherry picker truck. Individuals found in each chamber (nestlings and adults) were captured with small funnel nets (placed at the opening of each breeding chamber). In both sites trapping took place immediately after arrival of researchers at dusk, in order to minimize disturbance. We did not capture all adult individuals in nests, because some escaped when we were approaching the nets. We are almost certain however that all of the trapped individuals were roosting in the chambers where they were captured, as we did not find openings between chambers that could allow adults to move at the moment of trapping. We did not observe or mark the adult population in the area before the trapping day. Therefore, no information is available on the social status of the trapped adults besides their chamber location.

Individuals were blood-sampled, banded, and kept in cages. Early in the following morning nestlings were returned to the nest and adults were released near the capture site. A total of 28 nests were sampled (Miramar: 19, Marull: 9): 21 nests had a single chamber, six nests had two chambers, and one nest had four chambers. Average number of nestlings per chamber was 4.6 ( $\mathrm{SD}=1.6$, ranging between one and eight). A total of 196 individuals were genotyped (154 nestlings, and 42 adults, including 21 candidate fathers, 20 candidate mothers and one adult individual that we were unable to sex).

\section{DNA extraction and PCR amplifications}

Genomic DNA was extracted from blood samples according to the protocol 1 of salt extraction [24]. Seven loci of microsatellites were used for relatedness and parentage analyses: AgGT19, AgGT29, AgGT90 [25], MmGT046, MmGT054, MmGT057 and MmGT060 [26]. PCR reactions were performed in a Master cycler Eppendorf (Hamburg, Germany) in $10 \mu \mathrm{l}$ volume containing: ca. $10 \mathrm{ng}$ of DNA, $75 \mathrm{mM}$ Tris- $\mathrm{HCl} \mathrm{pH} \mathrm{8.8,}$ $20 \mathrm{mM}$ (NH4)SO4, 0.01\% Tween-20, $1 \mathrm{mM}$ of $\mathrm{MgCl} 2$ (1.5 mM of $\mathrm{MgCl} 2$ for AgGT90), $62.5 \mathrm{mM}$ of dNTPs, $20 \mu \mathrm{M}$ of each primer and $0.5 \mathrm{U}$ of Taq DNA polymerase (Fermentas, Brazil). Reaction conditions were the following: initial step at $95^{\circ} \mathrm{C}$ for $10 \mathrm{~min}, 30$ cycles at $95^{\circ} \mathrm{C}$ for $30 \mathrm{~s}, 57^{\circ} \mathrm{C}$ for $30 \mathrm{~s}, 72^{\circ} \mathrm{C}$ for $30 \mathrm{~s}$ and a final extension at $72^{\circ} \mathrm{C}$ for $10 \mathrm{~min}$. For AgGT29, MmGT046, MmGT054, MmGT057 and MmGT060 we employed a "touchdown" cycling program consisting of: $95^{\circ} \mathrm{C}$ for $10 \mathrm{~min}, 30$ cycles at $95^{\circ} \mathrm{C}$ for $30 \mathrm{~s}$, annealing for $30 \mathrm{~s}, 118$ and $72^{\circ} \mathrm{C}$ for $30 \mathrm{~s}$; and a final step at $72^{\circ} \mathrm{C}$ for $10 \mathrm{~min}$. The annealing step in the touchdown program decreased by $1^{\circ} \mathrm{C}$ every other cycle from $59^{\circ} \mathrm{C}$ until it reached $51^{\circ} \mathrm{C}$; at that point, the remaining cycles continued at an annealing temperature of $51^{\circ} \mathrm{C}$. Amplified fragments were separated through electrophoresis using Tris-Glycine buffer system on native polyacrylamide gels. We used 7\% acrylamide-bisacrylamide 19:1 for AgGT19, AgGT29, AgGT90, MmGT046, MmG T054 and MmGT057 and 8\% polyacrylamide gel for MmGT060. Gels were run at $280 \mathrm{~V}$ for $3 \mathrm{~h}$ and silver stained. Allele sizes were determined by comparison with a 10-bp DNA ladder molecular size standard (Invitrogen) (Additional file 3). The sex of adults was determined as indicated in [27], using the specific markers P2 and P8 for ZW sexual chromosomes. Only one adult from Marull was not sexed.

\section{Genetic analyses}

Allelic richness, observed and expected heterozygosity, and tests for deviation from $\mathrm{H}-\mathrm{W}$ equilibrium and linkage disequilibrium were performed with Arlequin 3.11 program [28], using default parameters and adult individuals only $(\mathrm{N}=42)$. A random sample of 36 nestlings, taking one nestling from each chamber and a combined data set of the adults and nestlings (78 individuals) was also used to explore H-W equilibrium (data not shown). The presence of null alleles was investigated in the whole data set using the software Micro-Checker v2.2.3 [29] and ML-Relate [30]. The latter program was used to adjust allelic frequencies for null alleles.

We performed a molecular analysis of variance (AMOVA) [31] in Arlequin 3.11 [28] using adult 
individuals only, to estimate the contribution of hierarchical partitions to genetic variation (i.e., between localities, among individuals within localities and within individuals). We also estimated if fixation indices were significantly different from zero by means of 1,000 permutations.

We estimated patterns of sexual monogamy according to Gonçalves da Silva et al. [6]. The hypothesis of sexual monogamy predicts that both adult-juvenile and nestlings within chambers should have relatedness values close to 0.5 and the relationship among chambers should have values of 0 [32]. We used iRel program to evaluate the power of our markers for assessing dyads to a certain relationship category (i.e., full-sibs). This program computes expected misclassification rates as the fraction misclassified out of 1,000 simulated pairs of each category, using cut-off values [33]. The calculation of pairwise $\mathrm{r}$ was based on the method described in Li et al. [34], with each locus weighted using the method described in Lynch \& Ritland [35] and Van de Casteele et al. [36] performed in Storm [37]. The test of significance was performed by comparing $95 \%$ confidence intervals around the mean.

We also used the program Storm [37] to calculate the mean relatedness (r) within chambers. This program provides a method to test the hypothesis that individuals within observed groups, in this case chambers, are more or less related than expected if the groups represented random associations of individuals with respect to relatedness. The calculation of $\mathrm{r}$ is based on the method described in Li et al. [34]. We performed 1,000 iterations of Monte Carlo simulations to generate expected distribution of average relatedness within a group. For each simulation, individuals were shuffled between groups keeping each group size constant. In addition, we estimated the average relatedness between chambers in those nests that had two or more chambers. To estimate 95\% confidence intervals of mean value of chicks within chambers, 10,000 parametric bootstrap replications were performed. The estimations were carried out with boot package in R 2.12.2 [38].

ML-Relate software was used to estimate the relationship among nestlings; this program uses a maximum likelihood approach and accommodates for the occurrence of null alleles. Together with $r$ values, the relationship estimated by ML-Relate was used to specify the kinship among nestlings from the same chamber or nest, when applicable.

Full-sibs and paternity and maternity of nestlings were identified by using the maximum likelihood method implemented in Colony 2.0.1.1 [39,40]. We used the full likelihood method option, the long option for the length of run and the allelic frequencies adjusted for null alleles. Longer runs are more likely to find the maximum likelihood configuration. According to the previous evidence, we selected the mating system option as "monogamous" and ran these parameters 10 times to find the best configuration. Finally, the possibility of parentage and sibship relationships from the other localities was excluded mutually.

Intraspecific brood parasitism was assumed in those broods with nestlings genetically unrelated with a) other nestlings in the clutch and, b) the genetic parents of the remaining nestlings (when data were available).

\section{Additional files}

\section{Additional file 1: Monk parakeet nestlings and adults found in each chamber, inferred relationships and probable mating system. \\ Additional file 2: Genetic variation at the seven microsatellite loci in adult individuals of monk parakeet (Myiopsitta monachus). \\ Additional file 3: Polyacrylamide gel electrophoresis patterns of microsatellite amplified in M. monachus using A) AgGT019, B) AgGT029, C) AgGT090, D) MmGT046, E) MmGT054, F) MmGT057, and G) MmGT060 markers. M: 10 bp ladder marker (Invitrogen); M1: $100 \mathrm{bp}$ ladder marker (Invitrogen). The chambers of provenance of each individual are indicated according to Figure 1}

\section{Competing interests}

The authors declare that they have no competing interests.

\section{Authors' contributions}

JJM collected the genetic data, analysed the data and contributed to the writing of the paper. MCdA helped collecting the genetic data, analysed the data and contributed to the writing of the paper. JFM designed the study, contributed to the field work and collection of samples, and reviewed several drafts and the final manuscript. EHB designed the study, collected samples in the field, performed research, and wrote the paper. All authors read and approved the final manuscript.

\section{Acknowledgements}

Fieldwork was partially funded by a co-operation grant between the IB of the BMBF of Germany (ARG 99/020) and the Argentinean SECYT (AL/ A99-EXIII/003). EHB research was partially funded by the US Fish and Wildlife Service, International Affairs division. MCdA and JJM want to thank Marina Chiappero for her valuable help during lab work at the beginning of this study. We thank Anja Quellmalz and Pablo Manzano Baena for valuable assistance during field work, and Erio Curto for allowing us to sample nests in his property in Marull, Córdoba. We also thank Emmi Schlicht and an anonymous reviewer, who provided valuable suggestions that improved the manuscript.

\section{Author details}

${ }^{1}$ Facultad de Ciencias Exactas, Físicas y Naturales, Universidad Nacional de Córdoba, Av. Vélez Sarsfield 299, (5000) Córdoba, Argentina. ²Ecología Marina. Instituto de Diversidad y Ecología Animal (CONICET-UNC) and Facultad de Ciencias Exactas, Físicas y Naturales, Universidad Nacional de Córdoba, Avenida Vélez Sarsfield 299, (5000) Córdoba, Argentina. ${ }^{3}$ Max Planck Institute for Ornithology, Vogelwarte Radolfzell, Radolfzell, Germany. ${ }^{4}$ Centro de Zoología Aplicada. Instituto de Diversidad y Ecología Animal (CONICET-UNC) and Facultad de Ciencias Exactas, Físicas y Naturales, Universidad Nacional de Córdoba, Avenida Vélez Sarsfield 299, (5000) Córdoba, Argentina. ${ }^{5}$ Present address: Departamento de Ciencias Naturales, Facultad de Ciencias Exactas, Físico-Químicas y Naturales, Consejo Nacional de Investigaciones Científicas y Técnicas (CONICET), Universidad Nacional de Río Cuarto, Ruta Nacional 36 Km 601, Río Cuarto 5800 Argentina.

Received: 7 July 2013 Accepted: 4 November 2013

Published: 9 November 2013 
References

1. Carrete M, Tella JL: Wild-bird trade and exotic invasions: a new link of conservation concern? Front Ecol Environ 2008, 6:207-211.

2. Pruett-Jones S, Tarvin KA: Monk Parakeets in the United States; population growth and regional patterns of distribution. In Proceedings of the 18th Vertebrate Pest Conference. Edited by Baker O, Crabb AC. David, California: University of California; 1998:55-58.

3. Spreyer MF, Bucher EH: Monk Parakeet. In The Birds of North America, No 322 Edited by Poole A. Philadelphia, PA: The Bird of North America, Inc; 1998.

4. Forshaw JM, Cooper WT: Parrots of the World. 3rd edition. Blandford, Willoughby, Australia: Edited by Lansdowne Editions; 1989.

5. Eberhard JR: Breeding biology of the Monk Parakeet. Wilson Bull 2008, 11:463-473.

6. Gonçalves da Silva A, Eberhard JR, Wright TF, Avery MF, Rusello MA: Genetic evidence for high propagule pressure and long-distance dispersal in monk parakeet (Myiopsitta monachus) invasive populations. Mol Ecol 2008, 19:3336-3350.

7. Martella MB, Bucher EH: Estructura del nido y comportamiento de nidificación de la cotorra Myiopsitta monachus. Boletín Sociedad Zoología Uruguay 1992, 8:211-217

8. Wagner AP, Creel S, Kalinowski ST: Estimating relatedness and relationships using microsatellite loci with null alleles. Heredity 2006, 97:336-345.

9. Spoon TR: Parrot reproductive behavior, or who associates, who mates, and who cares? In Manual of Parrot Behavior. Edited by Luescher AU. Ames, lowa, USA: Blackwell; 2006:63-77.

10. Masello JF, Sramkova A, Quillfeldt P, Epplen JT, Lubjuhn T: Genetic monogamy in burrowing parrots Cyanoliseus patagonus? J Avian Biol 2002, 33:99-103.

11. Griffith $S$, Owens IP, Thuman KA: Extra pair paternity in birds: a review of interspecific variation and adaptive function. Mol Ecol 2002, 11:2195-2212.

12. Taylor TD, Parkin DT: Preliminary evidence suggests extra-pair mating in the endangered echo parakeet, Psittacula eques. African Zool 2009, 44:71-74.

13. Caparroz R, Miyaki Y, Baker AJ: Genetic evaluation of the mating system in the blue-yellow macaw (Ara ararauna, Aves, Psittacidae) by DNA fingerprinting. Genet Mol Biol 2011, 34:161-164.

14. Rossmanith E, Grimm V, Blaum N, Jeltsch F: Behavioural flexibility in the mating system buffers population extinction: lessons from the lesser spotted woodpecker Picoides minor. J Anim Ecol 2006, 75:540-548.

15. Møller AP, Ninni P: Sperm competition and sexual selection: a meta-analysis of paternity studies of birds. Behav Ecol Sociobiol 1998, 43:345-358.

16. Westneat DF, Sherman PW: Density and extra-pair fertilizations in birds: a comparative analysis. Behav Ecol Sociobiol 1997, 41:205-215.

17. IICA: Reunión de Análisis de Situación y Medidas de Coordinación para el Control de Aves Plaga de la Agricultura en el Área Rioplatense Argentina-Uruguay. In Instituto Interamericano de Ciencias Agricolas. Argentina: Paraná, Entre Rios; 1987.

18. Aramburú RM: Nidadas supernumerarias en cotorra común (Myiopsitta monachus monachus). Ornitol Neotrop 1996, 7:155-156.

19. Navarro J, Martella M, Bucher E: Breeding season and productivity of monk parakeets in Cordoba, Argentina. Wilson Bull 1992, 104:413-424.

20. Yom-Tov Y: Intraspecific nest parasitism in birds. Biol Rev 1980, 55:93-108.

21. Beissinger $S$, Waltman JR: Extraordinary clutch size and hatching asynchrony of a neotropical parrot. Auk 1991, 108:863-871.

22. Rohwer EC, Freeman S: The distribution of conspecific nest parasitism in birds. Can J Zool 1989, 67:239-253.

23. Lyon BE, Eadie JM: Conspecific brood parasitism in birds: a life-history perspective. Annu Rev Ecol Evol Syst 2008, 39:343-363.

24. Bruford ME, Hanotte O, Brookfield JRY, Burke T: Single-locus and multilocus DNA fingerprinting. In Molecular genetic analysis of populations, a practical approach. Edited by Hoelzel A. Oxford: Oxford University Press; 1992:225-269.

25. Russello M, Calcagnotto D, DeSalle R, Amato G: Characterization of microsatellite loci in the endangered St. Vincent Parrot, Amazona guildingii. Mol Ecol Notes 2001, 3:162-164.

26. Russello MA, Saranathan V, Buhrman-Deever S, Eberhard J, Caccone A Characterization of polymorphic microsatellite loci for the invasive monk parakeet (Myiopsitta monachus). Mol Ecol Notes 2007, 6:990-992.

27. Griffiths R, Double MC, Orr K, Dawson RJ: A DNA test to sex most birds. Mol Ecol 1998, 7(Supple 8):1071-1075.

28. Excoffier L, Laval G, Schneider S: Arlequin ver. 3.0: an integrated software package for population genetics data analysis. Evol Bioinform Online 2005, 1:47-50.
29. Van Oosterhout C, Hutchinson WF, Wills DPM, Shipley P: Micro-checker: software for identifying and correcting genotyping errors in microsatellite data. Mol Ecol Notes 2004, 4:535-538.

30. Kalinowski ST, Wagner AP, Taper ML: ML-relate: a computer program for maximum likelihood estimation of relatedness and relationship. $\mathrm{Mol}$ Ecol Notes 2006, 6:576-579.

31. Excoffier L, Smouse P, Quattro J: Analysis of molecular variance inferred from metric distances among DNA haplotypes: application to human mitochondrial DNA restriction data. Genetics 1992, 131:479-491.

32. Blouin MS, Parsons M, Lacaille V, Lotz S: Use of microsatellite loci to classify individuals by relatedness. Mol Ecol 1996, 5:393-401.

33. Russello M, Amato G: Ex situ population management in the absence of pedigree information. Mol Ecol 2004, 13:2829-2840.

34. Li CC, Weeks DE, Chakravarti A: Similarity of DNA fingerprints due to chance and relatedness. Hum Hered 1993, 43:45-52.

35. Lynch $M$, Ritland $K$ : Estimation of pairwise relatedness with molecular makers. Genetics 1999, 152:1753-1766.

36. Van de Casteele T, Galbusera P, Matthysen E: A comparison of microsatellite-based pairwise relatedness estimators. Mol Ecol 2001, 10:1539-1549.

37. Frasier TR: STORM: software for testing hypotheses of relatedness and mating patterns. Mol Ecol Resour 2008, 8:1263-1266.

38. R Development Core Team: R: A Language and Environment for Statistical Computing. Vienna, Austria: R Foundation for Statistical Computing; 2012

39. Wang J: Sibship reconstruction from genetic data with typing errors. Genetics 2004, 166:1963-1979.

40. Jones OR, Wang J: COLONY: a program for parentage and sibship inference from multilocus genotype data. Mol Ecol Resour 2010, 10:551-555.

doi:10.1186/1742-9994-10-68

Cite this article as: Martínez et al:: Genetic evidence of extra-pair paternity and intraspecific brood parasitism in the monk parakeet. Frontiers in Zoology 2013 10:68

\section{Submit your next manuscript to BioMed Central and take full advantage of:}

- Convenient online submission

- Thorough peer review

- No space constraints or color figure charges

- Immediate publication on acceptance

- Inclusion in PubMed, CAS, Scopus and Google Scholar

- Research which is freely available for redistribution 